\title{
IS IT ENOUGH TO JUST INCREASE THE HEIGHT OF SUB-ANTRAL BONE DURING MAXILLARY SINUS AUGMENTATION OR DOSE ITS DEPTH MATTER?
}

\author{
Mai Ahmed Haggag*
}

\begin{abstract}
Purpose: Many techniques for maxillary sinus floor elevation have been used prior to implant placement in case of sever sinus pneumatization. Two-stage lateral-window sinus lifting using titanium micromesh without bone grafting was carried out in the present study. The purpose of the study was a trail to solve a question, if it is enough to just increase the height of sub-antral bone or it is also important to elevate the Schneiderian membrane medio-laterally as much as possible to accommodate for dental implants later.
\end{abstract}

Materials and Methods: Seven patients (11 sinuses) were included. A titanium micromesh was shaped in a tick shape and placed into the sinus through a lateral window to maintain the elevated membrane in place. Immediate, 6-months and 9-months postoperative cone beam computed tomography $(\mathrm{CBCT})$ were performed to evaluate the relation between the medio-lateral extension of the mesh and the amount of the gained bone.

Results: When the height of the formed bone was related to the depth of the titanium mesh, no significant difference could be observed at either 6 or 9 months. However, when the depth of newly formed bone was compared against the depth of the titanium mesh, a high significant difference was noted at both 6 and 9 months.

Conclusion: At least two thirds of the sinus depth must be elevated to obtain adequate bone width for future implantation.

KEY WORDS: bone width, maxillary sinus, sinus lift, titanium mesh

\section{INTRODUCTION}

To develop any treatment plan for posterior maxilla, the status of the residual bone and maxillary sinus must be wisely considered. ${ }^{(1)}$ The maxilla is made up of spongy bone and has one of the least dense bones in oral cavity. ${ }^{(2)}$

The amount of residual bone may be limited by sinus pneumatization. Rehabilitation of this area with implant-supported fixed prostheses has usually been challenging. ${ }^{(1)}$

\footnotetext{
* Lecturer, Oral and Maxillofacial Surgery Department, Faculty of Dentistry, Mansoura University, Mansoura, Egypt.
} 
Some experimental studies describe a continuation of maxillary sinus pneumatization in adults after posterior tooth extraction. ${ }^{(3,4)}$ This phenomenon also known as the fourth expansion phenomenon of the maxillary sinus, ${ }^{(5)}$ which has been explained as a type of disuse atrophy. ${ }^{(3)}$

According to Wolff's law, bone tends to resorb following tooth loss as a result of the reduction in functional forces applied to it. ${ }^{(5)}$

Not only for implantation, pneumatization can pose a surgical hazard in terms of oro-antral communications following extraction, ${ }^{(6,7)}$ and endodontic surgery of the antral related teeth. ${ }^{(8)}$ It also increases the risk of introducing foreign bodies, root tips, or teeth displacement into the sinus cavity. ${ }^{(9)}$ and it is well known to affect orthodontic teeth movement. ${ }^{(10,11)}$

Sinus Lift can be considered as the only technique that enables the use of adequately long and optimally localized implants. ${ }^{(12)}$ There are two main approaches for maxillary sinus floor elevation. The first approach, lateral antrostomy, is the classic and the more commonly performed technique described by Tatum. Later on Summers advocated a second approach which is the crestal approach. ${ }^{(13)}$

If subantral bone height is less than $4 \mathrm{~mm}$ so two stage sinus lift with a healing period of 6 to 18 months before implantation is preferred. ${ }^{(14)}$

Bone Formation within The maxillary sinus is considered a unique condition. Generally, we gain our understanding about bone healing from studying the fracture healing and regeneration of bony defects. In case of maxillary sinus bone is not formed in a fracture or defect but it is formed beyond the skeletal contour. ${ }^{(15)}$

Several studies suggested that the elevation of the schneiderian membrane by itself stimulates the bone regeneration by a fibrin clot formation in the space created. This clot, which is stabilized and protected from external trauma and intra-sinus air pressure, would have the chance to stimulate the bone formation. ${ }^{(15,16)}$
The key point of the new guided bone regeneration strategy is to maintain the Schneiderian membrane in the highest possible position as by using simultaneous implantation. ${ }^{(15)}$ Moreover, this technique suggests that there should be a perfect membrane lifting without membrane tears.

Titanium mesh has been used for a many clinical applications in reconstructive implant surgery and reported positive results. (17) Its rigidity provides extensive space maintenance and prevents contour collapse; its elasticity prevents mucosal compression; its stability prevents graft displacement; and its plasticity permits bending, contouring, and adaptation to any unique bony defect. ${ }^{(18)}$

The common criterion of commercially available titanium mesh membranes is its macroporosity. This is supposed to play an important role in sustaining blood supply and is believed to enhance regeneration by improving wound stability through tissue integration and permitting diffusion of extracellular nutrients through the membrane. ${ }^{(19)}$

The inner layer of the periosteum is rich in cellular components, including osteoblasts. ${ }^{(20)}$ It has been supposed that the numerous pericytes in the abundant vasculature of the periosteum are a source of osteoprogenitor cells. ${ }^{(21)}$ Thus, titanium mesh (TM) is a potential tool for maintaining the osteogenic potential of the periosteum at the site where regeneration is required. ${ }^{(22)}$

\section{PATIENTS AND METHODS}

The present study was approved by the ethics committee of the Faculty of Dentistry, Mansoura University

\section{a) Patient selection:}

Seven patients seeking prosthetic rehabilitation of the posterior maxilla using dental implants were recruited in this study. Patients were selected from the Outpatient Clinic, Oral and Maxillofacial 
Surgery Department, Faculty of Dentistry, Mansoura University.

N.B.: (11 maxillary sinuses in these patients were lifted)

\section{Inclusion Criteria:}

1. Inadequate subantral bone height for conventional implant insertion $(\leq 5 \mathrm{~mm})$.

2. Adequate width for the residual alveolar ridge to accommodate dental implants.

3. Absence of any undercuts in buccal aspect of the ridge that could prevent future placement of dental implants.

4. No pathology of neighboring teeth.

5. Good oral hygiene.

6. Patients free from any apparently systemic disease.

7. Patients willing to comply with the instructions and follow up visits needed throughout the treatment time.

\section{Exclusion criteria:}

1. Active sinusitis.

2. Previous sinus surgery.

3. Major bony septa.

4. Heavy smokers.

1. Severe osteoporosis.

\section{b) Armamentarium used:}

Dentium Advanced Sinus Kit (DASK) (fig.2):

DASK Drills; DASK Drill \#4, DASK Drill \#5.

$\checkmark$ Sinus Elevation Instruments; XSE1L, XSE2L, XSE3L, XSE4L.

\section{c. Surgical Technique (antrostomy):}

Traditional sinus lift will be done as described by Tatum. ${ }^{(23)}$
Tissue preparation: done just before anesthesia, the surgical site was cleaned thoroughly with Betadine on a cotton swab Followed by application of topical anesthesia (for 1 to 2 minutes).

Administration of local anesthesia then crestal incision was made slightly palatal to provide adequate closure after completion of the procedure. A full thickness mucoperiosteal flap was elevated to expose the lateral wall of the maxilla. Taking releasing incisions resulting in a three-line mucoperiosteal pyramidal flap to provide adequate access and visualization to the entire ridge crest and lateral wall.

Total decortication of the created window was done using Dentium Advanced Sinus Kit (DASK). Thinning down of the lateral wall was made with DASK Drill \#4 or \#5 at a 45-degree angle till noticing the shadow of the schneiderian membrane. Move the DASK Drill \#4 or \#5 mesiodistally with a gentle pressure until getting a proper size and shape of the window. Then the membrane was gently detached from the boundary of the bony window using a dome-shaped sinus curette. After that membrane elevation is carried out by separating it from all the sinus walls till reaching the desired height.

A $0.1-\mathrm{mm}$ dynamic titanium micromesh (Leibinger, Stryker Co., Geneva, Switzerland) was then cut, bent and fixed to the lateral wall of the sinus with a minimum of two $1.5-\mathrm{mm}$ micro-screws.

Following, a titanium mesh will be used to elevate the sinus membrane and fixed to the external surface of maxilla with micro screws. The Flap was then repositioned and sutured with $4 / 0$ vicryl sutures.

All the previous steps were clarified in the clinical pictures of case (1) and case (2).

\section{Clinical Follow-Up}

Patients were recalled one week postoperatively for suture removal and evaluation of healing. 


\section{Evaluation}

Cone beam CT was used at 6 and 9 months postoperatively (as shown in cases $1 \& 2$ ) to evaluate:

- The correlation between the extension of the titanium mesh into the maxillary sinus and the amount of subantral bone filling (fig.1):

In order to assess whether the depth of extension of the titanium mesh $(\mathrm{Y})$ could affect the 3D filling of the subantral bone, we classified the elevated sinuses into two groups: those, in which the mesh

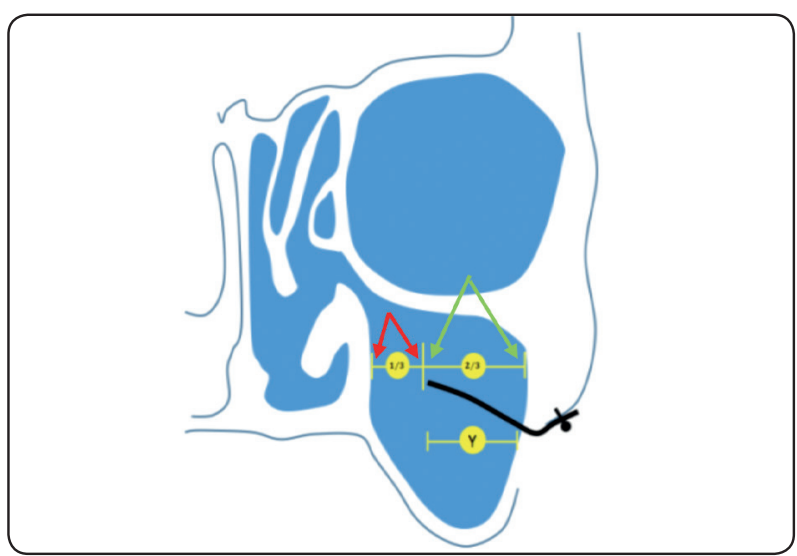

Fig. (1): Representing coronal view of the maxillary sinus; The titanium mesh extension inside maxillary sinus (Y), Green arrows represent the lateral two thirds of the mediolateral dimension of the maxillary sinus, Red arrows represent the medial one third of the mediolateral dimension of the maxillary sinus. extends more than two thirds the mediolateral dimension of the maxillary sinus and those in which the mesh extends less than two thirds of the distance.

\section{Statistical analysis:}

Data were tabulated, coded then analyzed using the computer program SPSS (Statistical package for social science) version 17.0 to obtain descriptive data. Data were considered statistically significant if the $\mathrm{p}$ value was $\leq 0.05$.

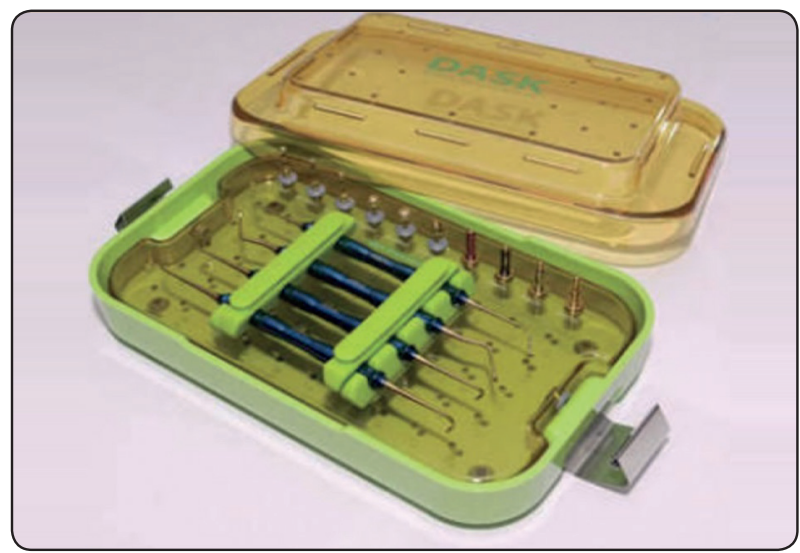

Fig. (2): Sinus elevation kit (DASK) (Dentium Catalogue)

Case (1) Radiographically: A 27 years old female patient, left sinus
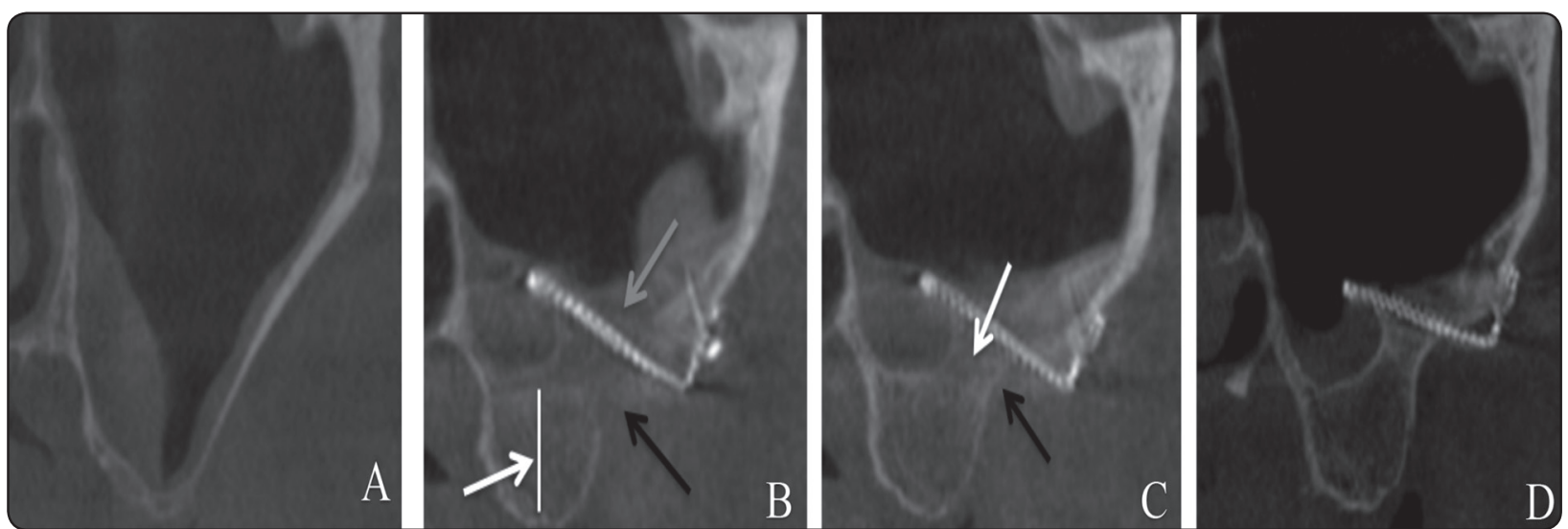

Preoperative CBCT parasagittal view shows sever pneumatization of maxillary sinus (A), 6 months postoperative CBCT parasagittal view \{white arrow for newly formed bone (trabeculation), Black arrow for unhealed bony window (buccal plate), Gray arrow for tick shaped titanium mesh\} (B), 9 months postoperative CBCT para-sagittal view showing healing of buccal plate (C), 12 months postoperative CBCT para-sagittal view showing complete bone maturation and incomplete bone filling (D) 


\section{Case (1) Clinically:}

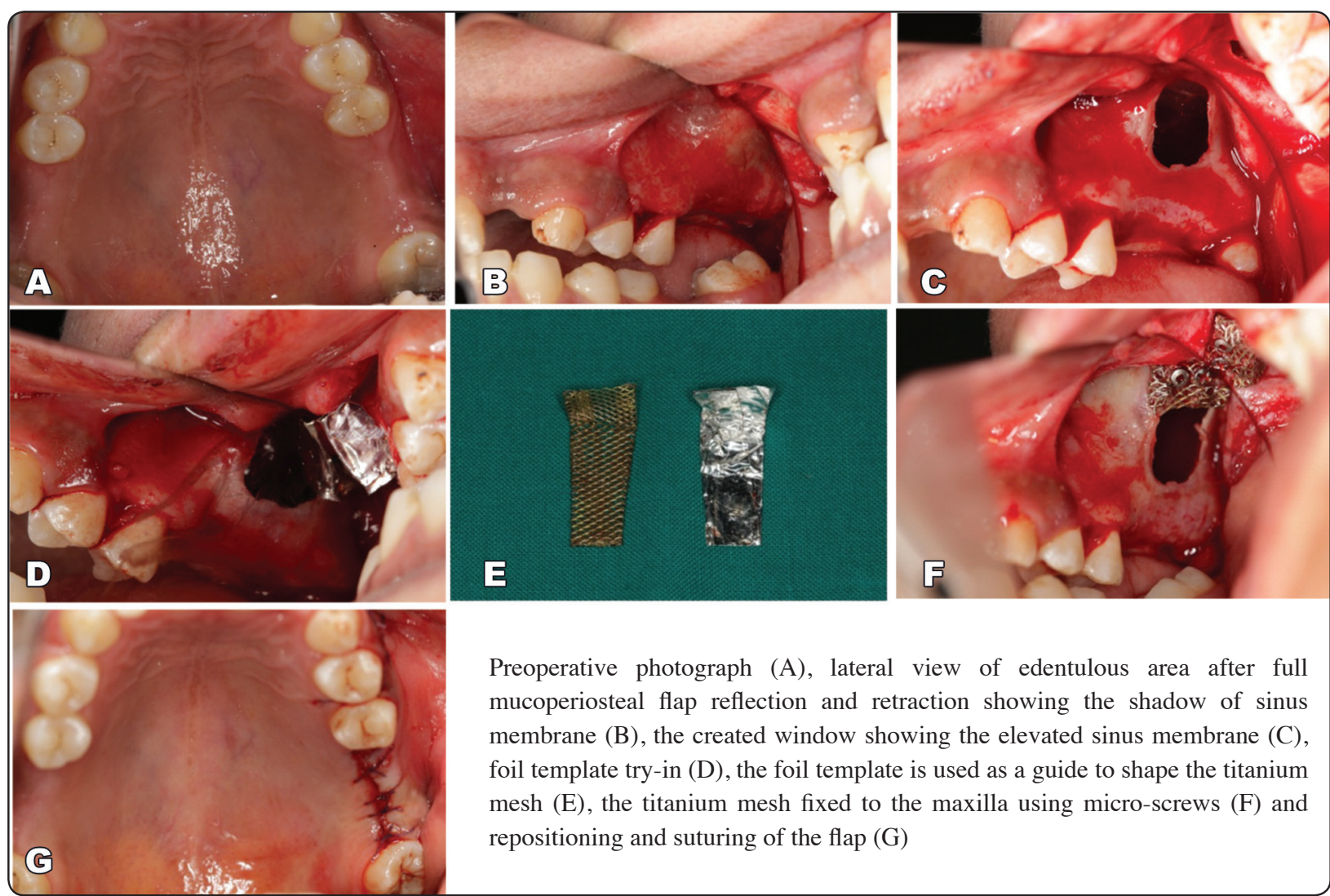

\section{Case (2) Radiographically: 27 years old female patient (right sinus).}

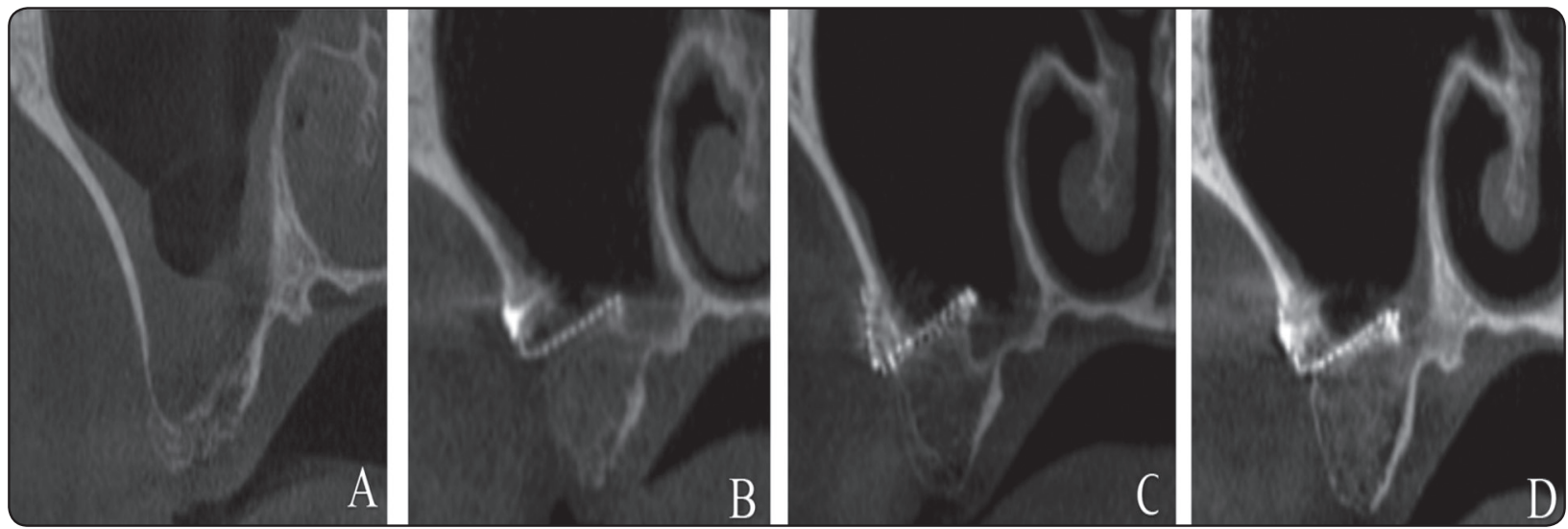

Preoperative CBCT parasagittal view showing sever pneumatization of maxillary sinus (A), 6 months' postoperative CBCT parasagittal view showing new bone formation which filled most of the created space mediolateral, Small area of low density below the titanium mesh that might indicate the presence of tissue for further healing (B), 9 months' postoperative parasagittal view CBCT showing more bone maturation $(\mathrm{C})$, complete bone formation and maturation also disappearance of the line separating native from new bone (D). 


\section{Case (2) Clinically:}

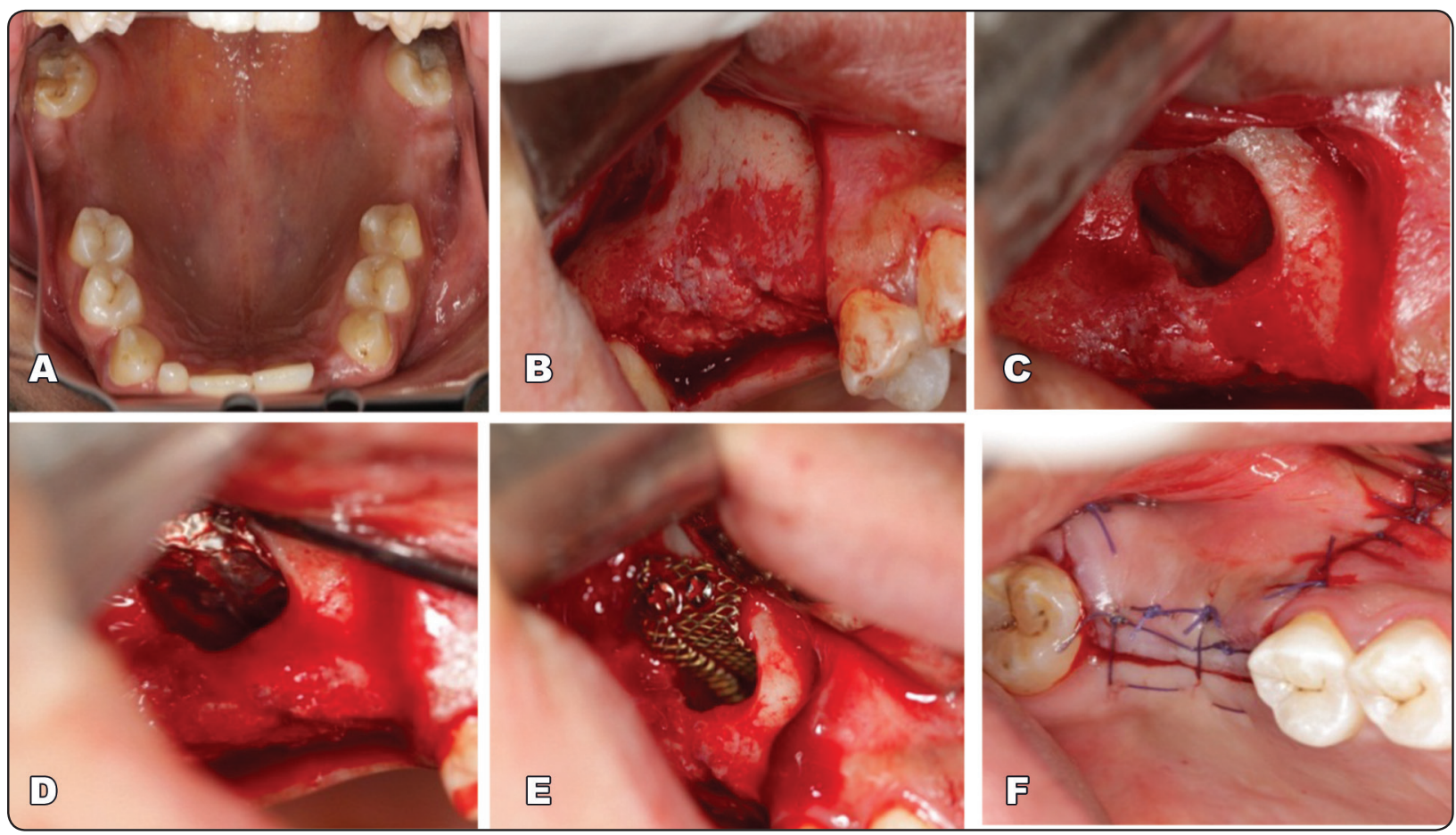

Preoperative photograph (A), lateral view of edentulous area after full mucoperiosteal flap reflection and retraction (B), the created window showing the elevated sinus membrane $(C)$, foil template try-in (D), the titanium mesh fixed to the maxilla using microscrews (E) and repositioning and suturing of the flap $(F)$

N.B. The results of 12 months postoperatively not included in the statistical analysis.

\section{RESULTS}

Seven patients, 5 males and 2 females; with the age ranging from 27 to 61 years and a mean age of 37.2 years were included in this study. A total number of 11 maxillary sinuses were lifted in an attempt to create adequate height of the alveolar ridge to accommodate future implant placement.
The correlation between the extension of the titanium mesh into the maxillary sinus and the amount of subantral bone filling:

When the height of the formed bone was related to the depth of the titanium mesh, no significant difference could be observed at either 6 or 9 months. However, when the depth of newly formed bone was compared against the depth of the titanium mesh, a high significant difference was noted at both 6 and 9 months. (Table 1) 
TABLE (1) The relation between the elevated sinus depth (Mediolaterally) and the newly formed bone height and depth (subantral bone fill) at 6 and 9 months postoperatively.

\begin{tabular}{|c|c|c|c|c|c|}
\hline & & $\begin{array}{l}\text { Elevat } \\
\text { (Mediola }\end{array}$ & $\begin{array}{l}\text { S depth } \\
\text { xtension }\end{array}$ & & \\
\hline & & & & & \\
\hline & Mean & \pm SD & Mean & \pm SD & \\
\hline Height of formed bone $(6 \mathrm{M})(\%)$ & 48.00 & 9.90 & 53.71 & 9.96 & 0.5 \\
\hline Height of formed bone $(9 \mathrm{M})(\%)$ & 73.50 & 21.92 & 72.14 & 11.01 & 0.9 \\
\hline Depth of formed bone (6M) (\%) (Mediolaterally) & 51.50 & 13.44 & 97.43 & 6.80 & $\leq 0.001 * *$ \\
\hline Depth of formed bone (9M) (\%) (Mediolaterally) & 68.50 & 12.02 & 100.00 & .00 & $\leq 0.001 * *$ \\
\hline
\end{tabular}

SD: Standard deviation, P: Probability, *: Significance $<0.05$, **: High significance $<0.001$, Test used: Student's t-test (Unpaired).

$<66 \%$; the titanium mesh extends to a distance less than two thirds of the mediolateral dimension of the maxillary sinus.

$>66 \%$; the titanium mesh extends to a distance more than two thirds of the mediolateral dimension of the maxillary sinus.

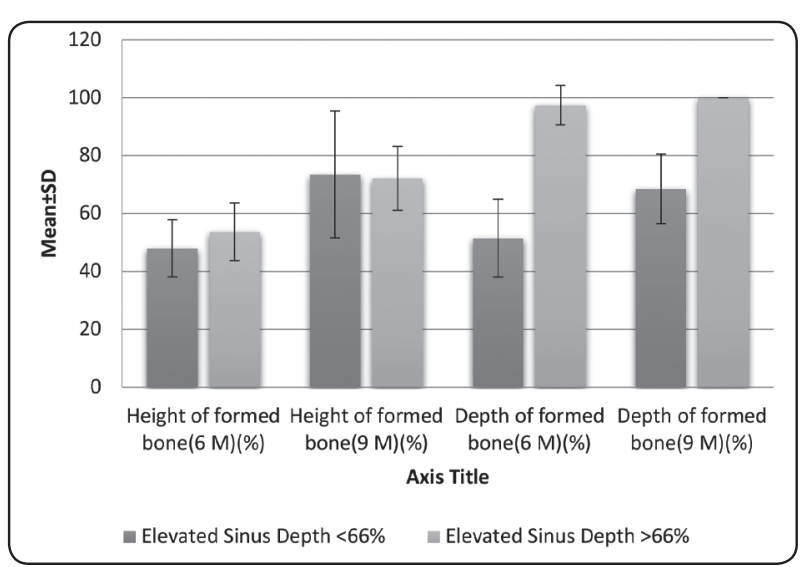

Chart (1) The relation between the elevated sinus depth (Mediolaterally) and the newly formed bone height and depth (subantral bone fill) at 6 and 9 months postoperatively.

\section{DISCUSSION}

There is no general consensus regarding the ideal space making device for sinus lift procedures. However, the ideal device should maintain the space and at the same time enhance the filling of the subantral space with the least complications.Cricchio and colleagues reported the use of a bioresorbable device. (24) Nevertheless, it was associated with intraoperative complications and at the same time negatively influenced the healing process. In the present study, the titanium micromesh was selected based on multiple advantages including excellent biocompatibility, tenting action, malleability and mechanical resistance. Being a non-resorbable device, it prevents future pneumatization even if the subantral space is left without grafting and/or implantation. It also protects the blood coagulum from the intra-sinus pressure. ${ }^{(15,16,17,18)}$

The titanium mesh used in the present study was able to efficiently maintain the created space in all postoperative follow up periods. This was in contrast to Schweikert and colleagues, who reported about $50.8 \%$ loss of the originally created apace. ${ }^{(25)}$

Maxillary sinus lift without grafting has different advantages. There is no risk of graft infection and no donor site morbidity. Absence of the graft material also eliminates the risk of postoperative sinusitis, which could occur as a result of graft displacement. (26-29)

The bone filling of the subantral space is reported to starts medially then gradually proceeds toward the distal antrostomy site. ${ }^{(30-33)}$ In contrast, the present study clearly demonstrated that bone starts to form at the lateral wall of the sinus and 
then extends medially. This could be attributed to the dropping of sinus membrane beyond the medial end of the mesh leading to slight instability of the blood clot beneath it, which negatively affects the healing process. ${ }^{(15,16)}$ To decrease the effect of the membrane dropping, we recommend extending the titanium mesh beyond two thirds the medio-lateral dimension of the sinus.

\section{SUMMARY}

This study was designed to evaluate the use of titanium micromesh (with adequate medio-lateral extension) for maxillary sinus floor elevation without any grafting to obtain adequate sub-antral bone for future dental implant placement.

\section{CONCLUSIONS}

At least two thirds of the sinus depth must be elevated to obtain adequate bone width for future implantation.

\section{REFERENCE}

1. Testori T. Maxillary sinus surgery: Anatomy and advanced diagnostic imaging. Journal of Implant and Reconstructive Dentistry. 2011; 3:18

2. Raja SV. Management of the posterior maxilla with sinus lift: Review of techniques. J Oral Maxillofac Surg. 2009; 67:1730-4

3. Wehrbein H, Diedrich P. Progressive pneumatization of the basal maxillary sinus after extraction and space closure [in German]. Fortschr Kieferorthop. 1992; 53:77-83

4. Ohba T, Langlais RP, Morimoto Y, Tanaka T, Hashimoto K. Maxillary sinus floor in edentulous and dentate patients. Indian J Dent Res. 2001; 12:121-5

5. Misch CE. Contemporary Implant Dentistry, ed 2. St Louis: Mosby, 1999 quoted from Sharan A, Madjar D. Maxillary sinus pneumatization following extractions: A radiographic study. Int J Oral Maxillofac Implants. 2008; 23:48-56

6. Güven O. A clinical study on oroantral fistulae. J CranioMaxillofac Surg. 1998; 26:267-71
7. Del Rey-Santamaría M., Valmaseda-Castellón E., BeriniAytés L., Gay-Es coda C. Incidence of oral sinus communications in 389 upper third molar extraction. Med Oral Patol Oral Cir Bucal. 2006; 11:334-8

8. Watzek G., Bernhart T., Ulm C. Complications of sinus perforations and their management in endodontics. Dent Clin North Am. 1997; 41:563-83

9. Jerome CE, Hill AV. Preventing root tip loss in the maxillary sinus during endodontic surgery. J Endod. 1995; 21:422-4

10. Fuhrmann R., Bücker A., Diedrich P. Radiological assessment of artificial bone defects in the floor of the maxillary sinus. Dentomaxillofac Radiol. 1997; 26:112-6

11. Sharan A, Madjar D. Maxillary sinus pneumatization following extractions: A radiographic study. Int J Oral Maxillofac Implants. 2008; 23:48-56

12. Šimůnek A, Kopecka D, Brazda T, Somanathan RV. Is lateral sinus lift an effective and safe technique? Contemplations after the performance of one thousand surgeries. Implantologie Journal. 2007;6

13. Summers RB. A new concept in maxillary implant surgery: the osteotome technique. Compend Contin Educ Dent. 1994; 15:152-62

14. Felice P, Pistilli R, Piattelli M, Soardi E, Barausse C, Esposito M. 1-stage versus 2- stage lateral sinus lift procedures: 1-year post-loading results of a multicentre randomised controlled trial. Eur J Oral Implantol. 2014; 7:65-75

15. Lundgren S, Andersson S, Gualini F, Sennerby L. Bone reformation with sinus membrane elevation: a new surgical technique for maxillary sinus floor augmentation. Clin Implant Dent Relat Res. 2004; 6:165-73

16. Hatano N, Sennerby L, Lundgren S. Maxillary sinus augmentation using sinus membrane elevation and peripheral venous blood for implant-supported rehabilitation of the atrophic posterior maxilla: Case series. Clin Implant Dent Relat Res. 2007; 9:150-5

17. Funato A, Ishikawa T, Kitajima H, Yamada M, Moroi H. A novel combined surgical approach to vertical alveolar ridge augmentation with titanium mesh, resorbable membrane, and rhPDGF-BB: a retrospective consecutive case series. Int J Periodontics Restorative Dent. 2013; 33:437-45.

18. Her S, Kang T, Fien MJ. Titanium mesh as an alternative to a membrane for ridge augmentation. J Oral Maxillofac Surg. 2012; 70:803-10 
19. Moroi A, Ueki K, Okabe K, Marukawa K, Sotobori M, Mukozawa A, Miyazakia M. Comparison between unsintered hydroxyapatite/Poly-L-lactic acid mesh and titanium mesh in bone regeneration of rabbit mandible. Implant Dent. 2013; 22:255-62

20. Allen MR, Hock JM, Burr DB. Periosteum: biology, regulation, and response to osteoporosis therapies. Bone. 2004; 35:1003-12

21. Diaz-Flores L, Gutierrez R, Lopez-Alonso A, Gonzalez R, Varela H. Pericytes as a supplementary source of osteoblasts in periosteal osteogenesis. Clin Orthop Relat Res.1992; 275:280-6

22. Dahlin C, Linde A, Gottlow J, Nyman S. Healing of bone defects by guided tissue regeneration. Plast Reconstr Surg. 1988; 81:672-6

23. Tatum $\mathrm{OH}$. Maxillary and sinus implant reconstruction. Dent Clin North Am. 1976; 30:207-29, quoted from Summers RB. A new concept in maxillary implant surgery: the osteotome technique. Compend Contin Educ Dent. 1994; $15: 152-62$

24. Cricchio G, Palma VC, Faria PEP, de Oliveira JA, Lundgren S, Sennerby L, Salata LA. Histological findings following the use of a space making device for bone reformation and implant integration in the maxillary sinus of primates. Clin Implant Dent Relat Res. 2009; 11:14-22

25. Schweikert M, Botticelli D, De Oliveira JA, Scala A, Salata LA, Lang NP. Use of a titanium device in lateral sinus floor elevation: an experimental study in monkeys. Clin Oral Implant Res. 2012; 23:100-5

26. Hernández-Alfaro F, Torradeflot MM, Marti C. Prevalence and management of Schneiderian membrane perforations during sinus-lift procedures. Clin Oral Implants Res. 2008; 19:91-8

27. Kahnberg KE, Vannas-Löfqvist L. Sinus lift procedure using a 2-stage surgical technique: I. Clinical and radiographic report up to 5 years. J Oral Maxillofac Implants. 2008; 23:876-84

28. Tidwell JK, Blijdorp PA, Stoelinga PJ, Brouns JB, Hinderks F. Composite grafting of the maxillary sinus for placement of endosteal implants. A preliminary report of 48 patients. Int J Oral Maxillofac Surg. 1992; 21:204-9

29. Younger EM, Chapman MW. Morbidity at bone graft donor sites. J Orthop Trauma. 1989; 3:192-5

30. Atef M, Hakam MM, ElFaramawey MI, Abou-ElFetouh A, Ekram M. Nongrafted Sinus Floor Elevation with a SpaceMaintaining Titanium Mesh: Case-Series Study on Four Patients. Clin Implant Dent Relat Res. 2014;16:893-903

31. Gassling V, Purcz N, Braesen JH, Will M, Gierloff M, Behrens E, Açil Y, Wiltfang J. Comparison of two different absorbable membranes for the coverage of lateral osteotomy sites in maxillary sinus augmentation: a preliminary study. J Craniomaxillofac Surg. 2013; 41:76-82

32. Margolin MD, Cogan AG, Taylor M, Buck D, McAllister TN, Toth C, McAllister BS. Maxillary sinus augmentation in the non-human primate: a comparative radiographic and histologic study between recombinant human osteogenic protein-1 and natural bone mineral. J Periodontol. 1998; 69:911-19

33. Avera SP, Stampley WA, McAllister BS. Histologic and clinical observations of resorbable and nonresorbable barrier membranes used in maxillary sinus graft containment. Int J Oral Maxillofac Implants. 1997; 12:88-94 